This item was submitted to Loughborough's Research Repository by the author.

Items in Figshare are protected by copyright, with all rights reserved, unless otherwise indicated.

\title{
Reducing muscle temperature drop post warm-up improves sprint cycling performance
}

PLEASE CITE THE PUBLISHED VERSION

http://dx.doi.org/10.1249/MSS.0b013e31826fba7f

PUBLISHER

(c) The American College of Sports Medicine

\section{VERSION}

AM (Accepted Manuscript)

\section{LICENCE}

CC BY-NC-ND 4.0

\section{REPOSITORY RECORD}

Faulkner, Steve H., Richard A. Ferguson, Nicola Gerrett, Maarten Hupperets, S.G. Hodder, and George Havenith. 2019. "Reducing Muscle Temperature Drop Post Warm-up Improves Sprint Cycling Performance". figshare. https://hdl.handle.net/2134/10288. 
This item was submitted to Loughborough's Institutional Repository (https://dspace.lboro.ac.uk/) by the author and is made available under the following Creative Commons Licence conditions.

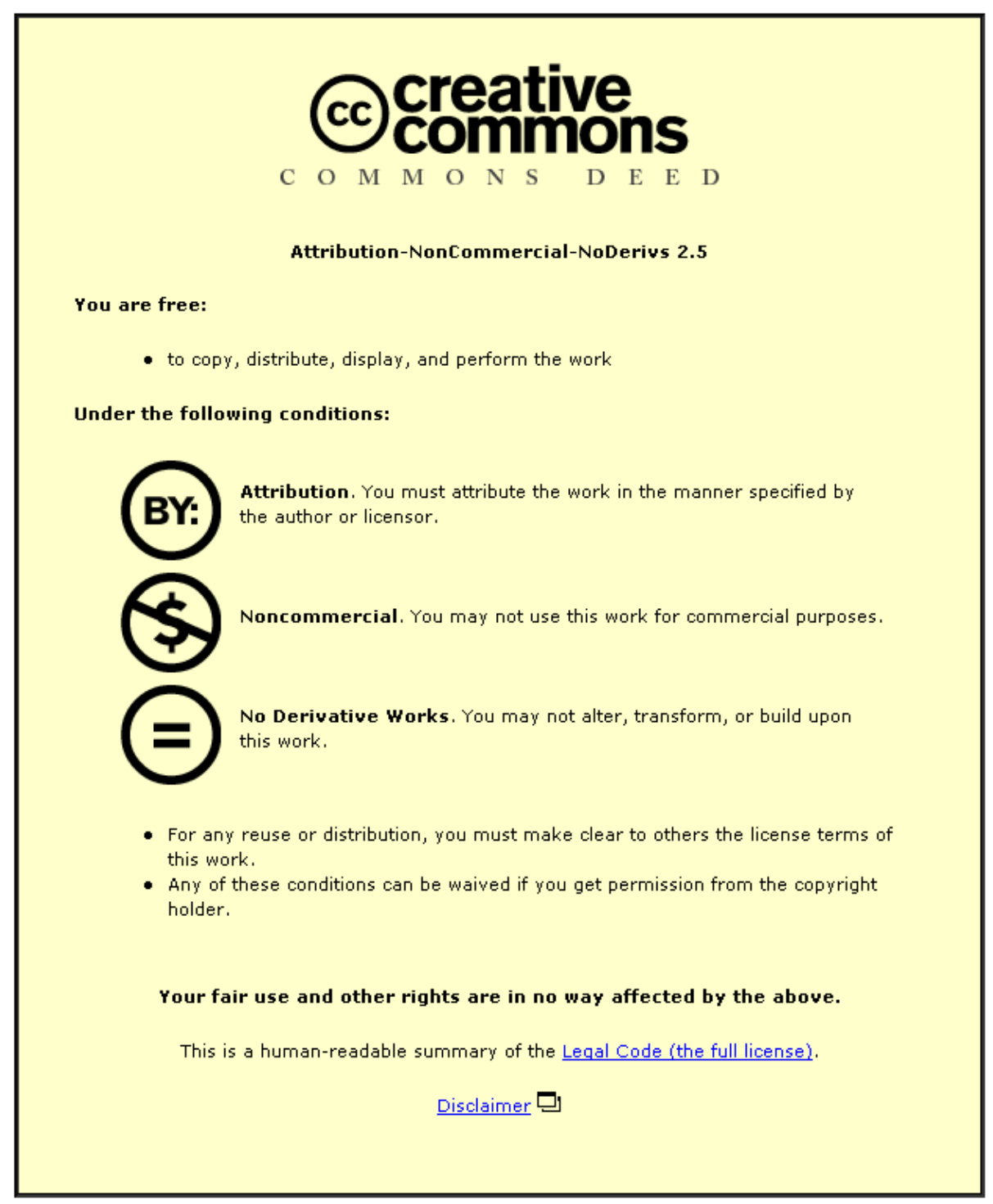

For the full text of this licence, please go to: http://creativecommons.org/licenses/by-nc-nd/2.5/ 


\title{
Reducing Muscle Temperature Drop Post Warm-Up Improves Sprint
}

\section{Cycling Performance}

\author{
Steve H. Faulkner ${ }^{1}$, Richard A. Ferguson ${ }^{2}$, Nicola Gerrett ${ }^{1}$, Maarten Hupperets ${ }^{3}$, Simon \\ G. Hodder ${ }^{1}$ and George Havenith ${ }^{1}$
}

${ }^{1}$ Environmental Ergonomics Research Centre, Loughborough Design School, Loughborough University, LE11 3TU, UK.

${ }^{2}$ School of Sport, Exercise and Health Sciences, Loughborough University, Leicestershire, LE11 3TU, UK.

${ }^{3}$ ait Sport Research Lab, adidas AG, 91074 Herzogenaurach, Germany

Corresponding Author: Prof George Havenith, Environmental Ergonomics Research Centre, Loughborough Design School, Loughborough University, LE11 3TU, UK.

Tel: $+44(0) 1509228485$.

Fax: +44 (0)1509 226900

E-mail: G.Havenith@,lboro.ac.uk

Running Title: Intervention Reducing Muscle Temperature Drop

Conflicts of Interest and Sources of Funding: The current research was co-funded by Adidas Innovation Team, Germany, and the Environmental Ergonomics Research Centre, Loughborough University, UK.

Declaration of conflicts of interest:

Steve Faulkner: None

Richard Ferguson: None

Nicola Gerrett: None

Simon Hodder: None

Maarten Hupperets: None

George Havenith: None 


\section{ABSTRACT}

Purpose: This study aimed to determine the effect of passive insulation versus external heating during recovery following a sprint specific warm up on thigh muscle temperature and subsequent maximal sprint performance. Methods: On three separate occasions, 11 male cyclists (age $24.7 \pm 4.2$ years, height $1.82 \pm 0.72 \mathrm{~m}$, body mass $77.9 \pm 9.8 \mathrm{~kg}$; mean \pm S.D.) completed a standardized 15 min intermittent warm up on a cycle ergometer, followed by a 30 min passive recovery period before completing a $30 \mathrm{sec}$ maximal sprint test. Muscle temperature was measured in the vastus lateralis at 1,2 and $3 \mathrm{~cm}$ depth prior to and following the warm up and immediately before the sprint test. Absolute and relative peak power output was determined and blood lactate concentration was measured immediately post-exercise. During the recovery period participants wore a tracksuit top and either i) standard tracksuit pants (CONT); ii) insulated athletic pants (INS) or; iii) insulated athletic pants with integrated electric heating elements (HEAT). Results: Warm up increased $\mathrm{T}_{\mathrm{m}}$ by approximately $2.5^{\circ} \mathrm{C}$ at all depths, with no differences between conditions. During recovery, $\mathrm{T}_{\mathrm{m}}$ remained elevated in HEAT compared to INS and CONT at all depths $(\mathrm{p}<0.001)$. Both peak and relative power output were elevated by $9.6 \%$ and $9.1 \%$ respectively in HEAT compared to CONT (both $\mathrm{p}<0.05$ ). The increase in blood lactate concentration was greater $(\mathrm{p}<0.05)$ post sprint in HEAT $(6.3 \pm 1.8 \mathrm{mmol} / \mathrm{L})$ but not INS $(4.0 \pm 1.8 \mathrm{mmol} / \mathrm{L}) \mathrm{vs}$. CONT $(4.1 \pm 1.9 \mathrm{mmol} / \mathrm{L})$. Conclusion: Passive heating of the thighs between warm up completion and performance execution using pants incorporating electrically heated pads can attenuate the decline in $\mathrm{T}_{\mathrm{m}}$ and improve sprint cycling performance.

Key Words: MUSCLE TEMPERATURE, POWER OUTPUT, PERFORMANCE, INSULATION, CLOTHING 


\section{Paragraph 1}

\section{INTRODUCTION}

It is well established that muscle temperature $\left(\mathrm{T}_{\mathrm{m}}\right)$ has a significant effect on muscle function. $(2,7,10,13,21,25)$. Much of the available literature suggests that events that are of short duration ( $<5$ minutes) and are more heavily reliant on high levels of power production tend to benefit from increases in muscle temperature $(2,17)$. For example, it has been demonstrated that there is a $\sim 4 \%$ per ${ }^{\circ} \mathrm{C}$ improvement in instantaneous power output during a vertical jump as $T_{m}$ increased (7). In addition, during short term $(<30 \mathrm{sec})$ maximal sprint cycling peak power output increases between 2 and $10 \%$ per ${ }^{\circ} \mathrm{C}$ as $\mathrm{T}_{\mathrm{m}}$ was elevated (25). In contrast to short term "sprint" based activities performance during endurance events may be impaired if the warm up results in depleted glycogen stores $(8,15)$ and an increase in thermoregulatory strain $(12,19)$. Therefore, it appears that the use of extensive warm ups, may be of most benefit for short duration activities that require high levels of short-term power output.

\section{Paragraph 2}

Muscle temperature in humans may be elevated in one of two ways. Firstly it can be achieved via an active warm up, involving exercise that induces increases in metabolic activity and heat production within the body. Active warm ups are commonly completed using a method which mimics the activity for which the warm up is done, such as running, swimming or cycling (9). Following 15 minutes of active warm up, $\mathrm{T}_{\mathrm{m}}$ has been shown to increase by approximately $3-4^{\circ} \mathrm{C}$ at depth of $2-4 \mathrm{~cm}$ (9). Secondly, passive heating, which involves the use of an external heat source to add heat to the desired muscles, can be used to elicit a rise in $\mathrm{T}_{\mathrm{m}}$. This is commonly done using water immersion $(16,25)$, warm air exposure (27) or heating pads (16). Grey et al. have demonstrated that with a combination of 30 minutes warm water immersion followed by passive heating using electric blankets, $\mathrm{T}_{\mathrm{m}}$ can be elevated by approximately $3^{\circ} \mathrm{C}$ at a depth of $3 \mathrm{~cm}(16)$. 


\section{Paragraph 3}

Although most athletes perform some sort of warm up technique in preparation for their specific athletic event it is common for athletes to experience delays between completion of the warm up and the start of competition or where there are delays between repeated efforts/rounds of competition. These periods of time may be sufficient for $T_{m}$ to drop below an optimal level which may have a detrimental effect on performance, possibly due to the temperature related effect on power output. Currently, there is very little information about the exact effect a standardized sprint based warm up has on muscle temperature, and what the rate of decline in $\mathrm{T}_{\mathrm{m}}$ is following warm up cessation.

\section{Paragraph 4}

It is also logical to suggest that if $\mathrm{T}_{\mathrm{m}}$ can be artificially maintained following a warm up by the use of insulative clothing or clothing incorporating a form of external heating it may yield a performance benefit in subsequent activities that require high levels of power output. Therefore, the aim of this study was to examine how different ways of externally insulating the thigh muscles with either an insulated pant or a combined heated and insulated pant would influence $\mathrm{T}_{\mathrm{m}}$ during a recovery period following a standardized warm up procedure, and subsequently whether power output during a $30 \mathrm{sec}$ maximal sprint test would be affected. To our knowledge, this is the first study to directly assess the impact of an extended delay between warm up completion and sprint performance on muscle temperature, its impact on performance and in particular the use of an applied method of attenuating any apparent $T_{m}$ drop. It was hypothesized that added insulation, and moreover the combination of heating and insulation would result in better maintenance of $\mathrm{T}_{\mathrm{m}}$ following a warm up and contribute to elevated power output in the subsequent trial.

\section{Paragraph 5}




\section{METHODS}

\section{Participants}

11 male competitive cyclists and triathletes (age $24.7 \pm 4.2$ years, height $1.82 \pm 0.72 \mathrm{~m}$, body mass $77.9 \pm 9.8 \mathrm{~kg}$; mean \pm S.D.) volunteered to participate in this study. All participants performed at least 3 cycle based training sessions per week. Participants completed a general health-screening questionnaire and were non-smokers and free from injury. They were informed of the requirements of the study before giving written informed consent. A repeated measures study design was used, with each participant testing all three interventions in an order balanced manner. All procedures were approved by the Loughborough University Ethical Advisory Committee.

\section{Paragraph 6}

\section{Study Overview}

Prior to the main experimental trials, participants were familiarised with the nature of the exercise testing and general measurement procedures. For this, participants completed at least four 30 s maximal sprint tests separated by approximately 10 minutes of passive recovery. Trials were continued until the time to peak power output and peak power output showed minimal deviation, with peak power values within $5-10 \%$, and time to peak power within 0.2s. Participants visited the laboratory on three further occasions at the same time of day to minimize circadian variation. On each occasion they completed a 15-minute standardized cycle sprint based warm up followed by 30 minutes passive recovery. During the 30 -minute recovery period, participants underwent one of three experimental interventions (details below) before completing a 30 second maximal sprint performance test on a cycle ergometer. All trials were completed in a balanced order, separated by a minimum of 72 hours. In the 24 hours prior to each trial, participants were asked to refrain from caffeine and alcohol ingestion and any strenuous exercise. They were also asked to keep a record of their food 
intake and replicate this prior to the subsequent visits. Experiments were performed in an environmental chamber maintained at $15.9 \pm 0.3^{\circ} \mathrm{C}$ and $54.0 \pm 4.0 \%$ relative humidity.

\section{Paragraph 7}

\section{Experimental Protocol}

Participants attended the laboratory following a minimum of a four-hour fast, during which time they were allowed to consume water only. On arrival, participants voided and had their height (Seca, Birmingham, UK) and body mass (ID1 Multi Range, Sartorius, Goettingen, DE) recorded. Participants then inserted a rectal probe (Grant Instruments Ltd., UK) $10 \mathrm{~cm}$ beyond the anal sphincter to allow for monitoring of core temperature $\left(T_{c}\right)$.

\section{Paragraph 8}

Participants entered the environmental chamber and remained seated for 30 minutes wearing a standard tracksuit to allow for stabilisation of muscle and core temperature. After the stabilisation period, baseline measures for thermal sensation, thermal comfort, core temperature $\left(T_{c}\right)$, heart rate, blood lactate concentration and muscle temperature $\left(T_{m}\right)$ were taken. Participants then mounted an electronically braked cycle ergometer (Lode Excalibur Sport, Groningen, The Netherlands) and performed the standardized warm-up exercise which consisted of 5 minutes cycling at an external power output of $100 \mathrm{~W}$, followed by five $10 \mathrm{sec}$ maximal sprints, with each sprint separated by $1 \mathrm{~min} 50 \mathrm{sec}$ of cycling at $75 \mathrm{~W}$. Participants were instructed to maintain a cadence of $85 \mathrm{rpm}$, until the start of each sprint. The maximal sprints were performed at a frictional load equivalent to $10 \%$ body mass, which has been shown to be optimal for well trained athletes $(5,11)$. Immediately on completion of the warm up exercise, participants dismounted from the ergometer and $\mathrm{T}_{\mathrm{m}}$ was measured. In addition, measurements for $T_{c}$, heart rate, blood lactate concentration, thermal sensation of the legs and whole body and thermal comfort (legs and whole body) were made. Participants then donned a standard tracksuit top (adidas Clima365, adidas AG, Germany), and one of the three types 
of pant that made up the intervention: 1) control (CONT) where participants wore commercially available tracksuit pants (adidas Clima365, adidas AG, Germany) 2) insulation only (INS), where participants wore a pair of insulated athletic pants; 3) insulation plus heating (HEAT), where participants wore the same insulated pant with the addition of a heating element located around the thigh. The element was designed to cover the vastus medialis, rectus femoris, vastus latralis, biceps femoris, semitendinosus and semimembranosus of both legs. There was no coverage directly over the adductor muscles to allow for some variation in leg size between subjects, but the heating element remained in close contact with both thighs in all participants. The heating element was capable of reaching temperatures of $40-42^{\circ} \mathrm{C}$ and was powered by a $14.8 \mathrm{~V}$ battery that generated $7.5 \mathrm{~W}$ to each heating pad. Once donned the participant remained in the environmental chamber in a seated position for 30 minutes. During this period measurements of thermal comfort, thermal sensation, heart rate and $\mathrm{T}_{\mathrm{c}}$ were made every 5 minutes. At the end of the 30 -minute recovery the tracksuit top and pants were removed and a further $T_{m}$ measurement was made, along with measures of thermal sensation, thermal comfort, core temperature, heart rate and capillary blood lactate concentration. The participant then remounted the cycle ergometer and performed a 30 s maximal sprint test with a frictional load equivalent to $10 \%$ body mass. The sprint test was preceded by a $15 \mathrm{sec}$ period of cycling against $75 \mathrm{~W}$ at a pedal cadence of 85 rpm. A further blood sample was taken within 20 s of completion of the sprint.

\section{Paragraph 9}

\section{Measurements}

Power output and pedal cadence

Power output and pedal frequency were recorded continuously (at a sampling rate of $10 \mathrm{~Hz}$ ) throughout the warm up and sprint tests (Wingate Test Plus Module, Lode, Groningen, The Netherlands). Peak, minimum and mean power output, time to peak power, peak pedal 
cadence and time to peak pedal cadence were determined. Peak power was determined as the highest power output recorded at any individual time point within the 30 s maximal sprint test. Mean power was calculated using the average of all collected samples. Fatigue index was calculated as the change in power output divided by peak power multiplied by 100 .

\section{Paragraph 10}

\section{Muscle temperature}

Muscle temperature of the vastus lateralis of the left leg was measured at depths of $3 \mathrm{~cm}, 2$ $\mathrm{cm}$ and $1 \mathrm{~cm}$ using a needle thermistor probe with a temperature measurement range of $15-45$ $\pm 0.1^{\circ} \mathrm{C}$ (MKA08050A275T, Ellab, Copenhagen, Denmark). The needle probe was inserted to an initial depth of $3 \mathrm{~cm}$ beyond the muscle fascia where the temperature was allowed to stabilise for $5 \mathrm{~s}$ at each depth before the probe was withdrawn to $2 \mathrm{~cm}$ and then $1 \mathrm{~cm}$ depths, with the temperature recorded at each depth. Given the time constant of the thermal probe (xx seconds) this was deemed sufficient time to reach a stable value.

\section{Paragraph 11}

Heart rate, thermal sensation and blood lactate concentration

Heart rate (HR) was recorded using a wireless heart rate monitor (RS800, Polar, Kempele, Finland). Thermal sensation (TS) (1) and thermal comfort (TC) (14) were recorded. Whole blood, capillary blood samples $(\sim 5 \mu \mathrm{l})$ were taken from the finger-tip and analyzed immediately using an automated blood lactate analyzer (Lactate Pro, Arkray, Shiga, Japan). The use of which has been demonstrated to closely correlate with larger, laboratory constrained lactate analysers $(4,20)$.

\section{Paragraph 12}

\section{Calculations}

The temperature dependence (temperature coefficient, $\mathrm{Q}_{10}$ ) of both absolute and relative power output is presented as temperature coefficients $\left(\mathrm{Q}_{10}\right)$, calculated as follows $(6)$ : 


$$
Q_{10}=\left(R^{2}-R^{1}\right)^{10 /\left(T_{2}-T_{1}\right)}
$$

Where $R_{2}$ and $R_{1}$ represent rate processes for changes in power output respectively at temperatures $T_{2}$ and $T_{1}$, with $T_{2}$ being greater than $T_{1}$ following the warm up. A $Q_{10}$ value of $>1.0$ indicates a positive thermal dependence; a $\mathrm{Q}_{10}=1$ indicates a thermal independence and $\mathrm{Q}_{10}<1.0$ indicates a negative thermal dependence.

\section{Paragraph 13}

Clothing insulation

Insulation values for the heated pants for the legs and hips and whole body were determined using a thermal manikin (Newton, MTNW, Seattle, US) with a uniform skin temperature of $34^{\circ} \mathrm{C}$ and environmental temperature of $21^{\circ} \mathrm{C}$. For dry heat insulation the following equation was used (18):

$$
I_{T}=\frac{\bar{T}_{s k}-T_{a}}{\sum\left(\alpha_{i} \cdot H_{i}\right)}
$$

where $a_{i}=($ surface area of segment $i) /($ total surface area of manikin $) ; I_{\mathrm{T}}=$ total insulation of complete ensemble including enclosed and surface air layers $\left(\mathrm{m}^{2} \cdot \mathrm{K} \cdot \mathrm{W}^{-1}\right) ; T_{a}=$ ambient temperature; $\bar{T}_{s k}=$ mean skin temperature; $H_{i}=$ heat loss of segment $I(\mathrm{~W})$.

\section{Paragraph 14}

\section{STATISTICS}

Performance data were analysed using repeated measures ANOVA. $\mathrm{T}_{\mathrm{m}}$, thermal sensation, thermal comfort, $\mathrm{T}_{c}, \mathrm{HR}$ data were analysed using two way repeated measures ANOVA (condition $\mathrm{x}$ time). Where significant effects were identified, post-hoc pairwise comparisons 
with a Bonferonni correction were conducted. The accepted level of significance was $\mathrm{p}<$ 0.05. Data are presented as mean \pm S.D.

\section{Paragraph 15}

\section{RESULTS}

\section{Clothing Insulation}

When the heating element was inactive the insulation value of the insulated pants alone was $0.438 \mathrm{~m}^{2} . \mathrm{K} / \mathrm{W}$ (2.8 clo), with whole body insulation, comprising of the tracksuit top and insulated pants being $0.241 \mathrm{~m}^{2} . \mathrm{K} / \mathrm{W}$ (1.6 clo). When the heating element was activated, insulation of the legs and hips increased by $0.378 \mathrm{~m}^{2} . \mathrm{K} / \mathrm{W}(2.4 \mathrm{clo})$ to give a total insulation for the pants of $0.815 \mathrm{~m}^{2} . \mathrm{K} / \mathrm{W}$ (5.3 clo), with whole body insulation increasing to 0.263 $\mathrm{m}^{2} . \mathrm{K} / \mathrm{W}(1.7$ clo). Effective insulation values for the heated pants will be even higher than those reported here (18). As the heating input from the pants reduces the manikin heat loss to zero, and even warms up the manikin, the measured values underestimate the full impact of the heating. Nevertheless, the observed values provide an indication of the lowest estimate of the effect size of the added heating.

\section{Paragraph 16}

Muscle temperature

There were no differences in $\mathrm{T}_{\mathrm{m}}$ at any depths prior to the warm up in any condition. Immediately following the completion of the warm up $\mathrm{T}_{\mathrm{m}}$ increased at all depths and was the same between conditions (Figure 1). Following the recovery period, $\mathrm{T}_{\mathrm{m}}$ declined in all conditions, however, remained higher during HEAT at all depths compared to CONT and INS $(p<0.0005)$.

\footnotetext{
***figure 1 near here ***
} 
The difference in $T_{m}$ at the three depths between conditions following the recovery period is further highlighted in Figure 2, which shows the $\mathrm{T}_{\mathrm{m}}$ gradient for all three conditions at 30REC.

$$
* * * \text { figure } 2 \text { near here*** }
$$

\section{Paragraph 17}

\section{Power output and pedal cadence}

Absolute and power output per kilogram of bodyweight (relative peak power output, W. $\mathrm{kg}^{-1}$ ), were higher in HEAT compared to CONT $(\mathrm{p}<0.05)$ by $9.6 \%$ and $9.1 \%$ respectively (Table 1$)$ with 9 of the 11 participants showing a clear improvement in peak power output in the HEAT condition, with the remaining 2 showing no difference in peak power output compared to CONT. For INS vs CONT, 2 of the 11 participants showed slight improvements in power output, with the remaining 9 showing no improvement or lower peak power. Absolute peak power output had a strong positive thermal dependence $\left(\mathrm{Q}_{10}=2.4\right.$ at $1 \mathrm{~cm}, 2.5$ at 2 and $\left.3 \mathrm{~cm}\right)$ as did relative peak power output $\left(\mathrm{Q}_{10}=2.2\right.$ at all depths $)$. There were no significant differences in absolute or relative peak power output between HEAT and INS or between INS and CONT (Table 1). There was no effect of condition on mean power output, minimum power output, time to peak power output, peak cadence or time to peak cadence (Table 1). There was an overall effect of condition on fatigue index $(p<0.05)$, but no significant differences between individual conditions (Table 1).

\footnotetext{
*** Table 1 near here $* * *$
}

\section{Paragraph 18}

\section{Blood lactate concentration}

Following the warm up, blood lactate concentration increased $(\mathrm{p}<0.05)$ and was the same in all conditions. After the recovery period blood lactate concentration declined in all 
conditions but remained higher $(\mathrm{p}<0.01)$ in INS compared to HEAT (Figure 3 ). Following the maximal sprint test, blood lactate concentration increased $(p<0.05)$ in all conditions and was higher in HEAT compared to CONT $(\mathrm{p}<0.05)$. Moreover, the change in blood lactate concentration during the sprint test was greater $(\mathrm{p}<0.05)$ in HEAT $(\Delta=6.3 \pm 1.8 \mathrm{mmol} / \mathrm{L})$ compared to $\operatorname{CONT}(\Delta=4.1 \pm 1.9 \mathrm{mmol} / \mathrm{L})$.

\section{***figure 3 near here***.}

\section{Paragraph 19}

Heart rate and rectal temperature

There was no effect of condition on either heart rate or core temperature during the trials (table 2).

$$
* * * \text { table } 2 \text { near here*** }
$$

\section{Paragraph 20}

\section{Thermal sensation and comfort}

Thermal sensation of the legs was higher towards "warm" in the legs for HEAT compared to CONT at the following time points: 10REC $(p<0.05), 15 \operatorname{REC}(p<0.005), 20 \operatorname{REC}(p<0.001)$, 25REC $(p<0.05)$ and 30REC $(p<0.0005)$. There were also elevations in thermal sensation for INS vs CONT at the following: 20REC $(p<0.001)$ and INS vs HEAT at 25REC $(p<0.05)$. Thermal comfort for the whole body or legs between conditions was the same at all time points (figure 4).

$$
* * * \text { figure } 4 \text { near here*** }
$$

\section{Paragraph 21}

\section{DISCUSSION}

This study has demonstrated that the use of an insulated garment combined with internal heating elements around the thigh attenuated the decline in muscle temperature that occurs 
following a sprint specific cycling warm-up, while an insulated garment alone did not. The heated garment resulted in a muscle temperature that was approximately $1^{\circ} \mathrm{C}$ higher at a depth $1 \mathrm{~cm}$ and $0.4^{\circ} \mathrm{C}$ higher at $3 \mathrm{~cm} 30$ minutes after the warm-up compared to when no additional insulation or insulation only was provided. This was associated with a greater peak power output ( $\sim 9 \%)$ during a 30 s maximal sprint when muscle temperature was maintained with HEAT compared to CONT. The use of frictional load equivalent to $10 \%$ body mass during the 30 s sprint test has been shown to be optimal for well trained athletes $(5,11)$, thus leading to increased sensitivity of the test to detect changes in overall performance. Furthermore, the completion of a number of familiarisation sprint tests will have reduced any practice effects gained from repetition of the tests. Therefore allowing us to be confident that the results presented here are a true reflection of performance changes that would be mirrored in actual sprint competition. In support of this, it has been shown that 30 s of maximal sprinting on a cycle ergometer is moderately correlated to field based measures of sprint performance (3), suggesting that that the performance benefit reported in the present study will translate to improved field based sprint performance.

\section{Paragraph 22}

It is acknowledged that the $T_{m}$ probe used in the present study was unable to measure $T_{m}$ at all depth simultaneously. The time it took to take measurements at all three depths $(\sim 15 \mathrm{~s})$ is unlikely to significantly affect the $\mathrm{T}_{\mathrm{m}}$ measure recorded. It is possible that the external heating procedure used here could be applied in situations where athletes experience delays between warm up and competition, or where there are repeated efforts/rounds separated by periods of low to moderate activity which are not sufficient to maintain $T_{m}$ via metabolic heat production alone. Such scenarios are evident in many track and field athletics and track cycling competitions. 


\section{Paragraph 23}

The present data demonstrates that at depths of between $1-3 \mathrm{~cm}$ there is a $9 \%$ improvement in peak power output per ${ }^{\circ} \mathrm{C}$ elevation in $\mathrm{T}_{\mathrm{m}}$. This supports the notion that at a depth of between 1 and $4 \mathrm{~cm}$ with every $1{ }^{\circ} \mathrm{C}$ rise in muscle temperature there is an approximate $4-10 \%$ improvement in peak power output $(7,25)$, although this is dependent on pedal cadence $(25)$. The relationship between muscle temperature and skeletal muscle function has been well documented $(7,10,22,23,25)$, with increasing muscle temperature impacting upon the force/velocity relationship in both fast and slow twitch muscle fibres $(10,23)$. This interaction causes a shift in the force/velocity curve, resulting in increased peak power output with a temperature coefficient $\left(\mathrm{Q}_{10}\right)$ of $2-2.5(24)$. This is similar to the $\mathrm{Q}_{10}$ reported here $\left(\mathrm{Q}_{10}\right.$ 2.4), indicating that the in vivo thermal dependence of peak power output mirrors that documented in single fibre and animal models.

\section{Paragraph 24}

The increase in power output following HEAT is probably due to an elevated rate of ATP turnover as a consequence of the higher muscle temperature (16). This is reflected by the higher concentration of blood lactate following the maximal sprint in the HEAT condition. However, blood lactate concentration is dependent on many other factors including its rate of appearance and disappearance. Nevertheless, direct measurements of ATP turnover have shown ATP turnover to be elevated with increased muscle temperature. Gray et al., have shown that when muscle temperature is artificially elevated using water immersion of the legs, there is an increase in anaerobic ATP turnover during 6s maximal sprint cycling (16). Furthermore, in partial agreement with the present results they report an increase in both mean and maximal power output and peak pedal cadence following passive heating. During short-term maximal exercise, anaerobic metabolic pathways account for approximately 70$80 \%$ of ATP turnover $(28,29)$. Therefore, it would be expected that there was a higher 
concentration of blood lactate following the maximal sprint test when power output is elevated, as demonstrated here. However, it is possible that the differences in blood lactate concentration reported in the present study represent an increased vasodilatation in the HEAT condition resulting in faster blood lactate appearance, and may not necessarily directly indicate a greater anaerobic component of the 30s sprint test.

\section{Paragraph 25}

It can be seen as positive that the only significant difference in perceptual measures reported was a change in thermal sensation of the legs. These differences are likely due to the increased insulation and $\mathrm{T}_{\mathrm{sk}}$ in the HEAT condition. Had there been associated negative changes in thermal comfort as a result of the heating protocol, it is possible that performance would have been adversely affected. Despite the inherent difficulties in isolating thermal comfort from other physiological and thermal perceptions and their effects on exercise performance, Schlader et al., have demonstrated that elevations in pre-exercise thermal discomfort were associated with impaired cycling performance (26). Importantly, in the present study there were no differences in ratings of overall thermal comfort or thermal sensation, which indicates that the degree of heating was not perceived as more uncomfortable than when no heat was applied, and is therefore less likely to have a negative effect on performance.

\section{Paragraph 26}

\section{CONCLUSION}

This study has demonstrated that external heating of the quadriceps and hamstrings during periods of inactivity between exercise bouts can attenuate the reduction in $\mathrm{T}_{\mathrm{m}}$. Importantly, this leads to a significant and relevant improvement in peak power output compared to CONT and INS after 30 minutes of inactivity. This may have important practical implications for power athletes who may experience delays in their competition performance following 
the completion of a warm up or experience muscle cooling due to the intermittent nature of their sport or competition.

\section{Paragraph 27}

\section{Acknowledgements}

The authors would like to acknowledge the continued support from the adidas Innovation Team during this study, with special thanks to Dr. Berthold Krabbe. Further thanks must also go to Bryan Roberts and the Sports Technology Institute at Loughborough University for the loan of equipment.

\section{Paragraph 28}

The research presented was co-funded by the Adidas Innovation Team, Germany, and the Environmental Ergonomics Research Centre, Loughborough University. The authors were fully responsible for the conduct of the trial and the data.

The authors declare that there are no conflicts of interest.

The results from the present study do not constitute endorsement by the American College of Sports Medicine. 


\section{References}

1. ASHRAE. Thermal comfort. ASHRAE handbook of fundamentals. . (Atlanta, USA): 1997.

2. Asmussen E, O Boje. Body temperature and capacity for work. Acta Physiol Scand. $1945 ; 10: 1-22$.

3. Baker JS, B Davies. High intensity exercise assessment: relationships between laboratory and field measures of performance. J Sci Med Sport. 2002; 5(4):341-7.

4. Baldari C, V Bonavolonta, GP Emerenziani, MC Gallotta, AJ Silva, L Guidetti. Accuracy, reliability, linearity of Accutrend and Lactate Pro versus EBIO plus analyzer. Eur J Appl Physiol. 2009; 107(1):105-11.

5. Bar-Or O. The Wingate anaerobic test. An update on methodology, reliability and validity. Sports Med. 1987; 4(6):381-94.

6. Bennett AF. Thermal dependence of muscle function. Am J Physiol Regul Integr Comp Physiol. 1984; 247(2):R217-229.

7. Bergh U, B Ekblom. Influence of muscle temperature on maximal muscle strength and power output in human skeletal muscles. Acta Physiol Scand. 1979; 107(1):33-7.

8. Bergstrom J, L Hermansen, E Hultman, B Saltin. Diet, muscle glycogen and physical performance. Acta Physiol Scand. 1967; 71(2):140-50.

9. Bishop D. Warm up II: performance changes following active warm up and how to structure the warm up. Sports Med. 2003; 33(7):483-98. 
10. De Ruiter CJ, A De Haan. Temperature effect on the force/velocity relationship of the fresh and fatigued human adductor pollicis muscle. Pflugers Arch. 2000; 440(1):163-70.

11. Dotan R, O Bar-Or. Load optimization for the Wingate Anaerobic Test. Eur J Appl Physiol Occup Physiol. 1983; 51(3):409-17.

12. Drust B, P Rasmussen, M Mohr, B Nielsen, L Nybo. Elevations in core and muscle temperature impairs repeated sprint performance. Acta Physiol Scand. 2005; 183(2):181-90.

13. Edwards RH, RC Harris, E Hultman, L Kaijser, D Koh, LO Nordesjo. Effect of temperature on muscle energy metabolism and endurance during successive isometric contractions, sustained to fatigue, of the quadriceps muscle in man. $J$ Physiol. 1972; 220(2):335-52.

14. Gagge AP, JAJ Stolwijk, B Saltin. Comfort and thermal sensations and associated physiological responses during exercise at various ambient temperatures. Environ Res. 1969; 2(3):209-29.

15. Genovely H, BA Stamford. Effects of prolonged warm-up exercise above and below anaerobic threshold on maximal performance. Eur J Appl Physiol Occup Physiol. 1982; 48(3):323-30.

16. Gray SR, G De Vito, MA Nimmo, D Farina, RA Ferguson. Skeletal muscle ATP turnover and muscle fiber conduction velocity are elevated at higher muscle temperatures during maximal power output development in humans. Am J Physiol Regul Integr Comp Physiol. 2006; 290(2):R376-382.

17. Hajoglou A, C Foster, JJ De Koning, A Lucia, TW Kernozek, JP Porcari. Effect of warm-up on cycle time trial performance. Med Sci Sports Exerc. 2005; 37(9):1608-14.

18. Havenith G. Laboratory assessment of cold weather clothing. In: Textiles for cold weather apparel. Williams J (Ed.) Publishing in Textiles: Number 93 ed. Oxford Cambridge New Delh: Woodhead Publishing Limited; 2009. 
19. Marino FE. Anticipatory regulation and avoidance of catastrophe during exerciseinduced hyperthermia. Comp Biochem Physiol B Biochem Mol Biol. 2004; 139(4):561-9.

20. Pyne DB, T Boston, DT Martin, A Logan. Evaluation of the Lactate Pro blood lactate analyser. Eur J Appl Physiol. 2000; 82(1-2):112-6.

21. Racinais S, S Blonc, O Hue. Effects of active warm-up and diurnal increase in temperature on muscular power. Med Sci Sports Exerc. 2005; 37(12):2134-9.

22. Rall JA, RC Woledge. Influence of temperature on mechanics and energetics of muscle contraction. Am J Physiol. 1990; 259(2 Pt 2):R197-203.

23. Ranatunga KW. Force and power generating mechanism(s) in active muscle as revealed from temperature perturbation studies. The Journal of Physiology. 2010; 588(19):3657-70.

24. Ranatunga KW. Temperature dependence of mechanical power output in mammalian (rat) skeletal muscle. Exp Physiol. 1998; 83(3):371-6.

25. Sargeant AJ. Effect of muscle temperature on leg extension force and short-term power output in humans. Eur J Appl Physiol Occup Physiol. 1987; 56(6):693-8.

26. Schlader Z, S Simmons, S Stannard, T Mündel. Skin temperature as a thermal controller of exercise intensity. Eur J Appl Physiol. 2011; 111(8):1631-9.

27. Simmons SE, T Mundel, DA Jones. The effects of passive heating and head-cooling on perception of exercise in the heat. Eur J Appl Physiol. 2008; 104(2):281-8.

28. Smith JC, DW Hill. Contribution of energy systems during a Wingate power test. $\mathrm{Br}$ J Sports Med. 1991; 25(4):196-9.

29. Withers RT, WM Sherman, DG Clark, et al. Muscle metabolism during 30, 60 and 90 s of maximal cycling on an air-braked ergometer. Eur J Appl Physiol Occup Physiol. 1991; 63(5):354-62. 
Figure 1: Muscle temperature at 3, 2, and 1cm depth measured before the warm up (OWUP), immediately following the warm up (15WUP) and after 30 min seated recovery (30REC) in the control (CONT), insulation only (INS) and insulation + heating (HEAT). ${ }^{*}=$ HEAT > CONT $p<0.0005, \dagger=$ HEAT $>$ INS $p<0.0005$.

Figure 2: Muscle temperature measured at 3, 2 and $1 \mathrm{~cm}$ depth after $30 \mathrm{~min}$ seated recovery (30REC) in the control (CONT), insulation only (INS) and insulation + heating (HEAT). ** p $<0.005$ HEAT > CONT; †† $p<0.01$ HEAT > INS; * $p<0.0005$ HEAT $>$ CONT; $\dagger p<0.01$ HEAT > INS.

Figure 3: Blood lactate concentrations at baseline (0 WUP), following warm up (15 WUP), after passive recovery (30 REC) and immediately following the maximal sprint test (POST WIN) for control (CONT), insulation only (INS) and insulation + heating (HEAT). * = INS > HEAT $p<0.01 ; * *=H E A T>\operatorname{CONT} p<0.05$.

Figure 4: Subjective measures of A) thermal sensation of the legs and B) whole body thermal comfort for control (CONT), insulation only (INS) and insulation + heating (HEAT). * = HEAT $>$ CONT $p<0.005 ;{ }^{* *}=$ INS $>$ CONT $p<0.05 ; \dagger=H E A T>$ INS $p<0.05$.

Table 1: Peak power output (PPO), relative peak power output (rPPO), mean power output (Mean PO), minimum power output (min PO), peak cadence (Peak RPM), time to peak 
cadence and fatigue index for control (CONT), insulation only (INS) and insulation + heating (HEAT). All data presented as mean \pm S.D.

Table 2: Core temperature $\left(\mathrm{T}_{\mathrm{c}}\right)$, heart rate (H.R.M) following warm up (WUP 15), after 30 minutes passive recovery (30 REC) and immediately following the maximal sprint test (POST WIN) for control (CONT), insulation only (INS) and insulation + heating (HEAT) conditions. All data presented as mean \pm S.D.. 


\begin{tabular}{lccc}
\hline & CONT & INS & HEAT \\
\hline PPO $(\mathbf{W})$ & $1468 \pm 260$ & $1545 \pm 338$ & $1609 \pm 270^{*}$ \\
rPPO (W/Kg) & $19.2 \pm 1.7$ & $20.3 \pm 2.3$ & $20.9 \pm 1.6^{*}$ \\
Mean PO $(\mathbf{W})$ & $711 \pm 153$ & $707 \pm 127$ & $469 \pm 77$ \\
Min PO $(\mathbf{W})$ & $443 \pm 81$ & $435 \pm 136$ & $1.6 \pm 0.2$ \\
Time to peak PO (s) & $1.9 \pm 0.3$ & $1.8 \pm 0.2$ & $127.0 \pm 6.3$ \\
Peak cadence $(\mathbf{R P M})$ & $123.8 \pm 5.3$ & $124.3 \pm 6.2$ & $2.7 \pm 0.7$ \\
Time to peak cadence (s) & $3.4 \pm 0.8$ & $3.1 \pm 0.7$ & $74.2 \pm 4.3$ \\
Fatigue Index $(\%)$ & $68.8 \pm 8.2$ & $69.8 \pm 9.5$ & \\
\hline
\end{tabular}

* Significant difference between HEAT and CONT $(\mathrm{p}<0.05)$ 


\begin{tabular}{|c|c|c|c|c|c|c|c|c|c|}
\hline & \multicolumn{3}{|c|}{15 WUP } & \multicolumn{3}{|c|}{30 REC } & \multicolumn{2}{|c|}{ POST WIN } & \multirow[b]{2}{*}{ HEAT } \\
\hline & CONT & INS & HEAT & CONT & INS & HEAT & CONT & INS & \\
\hline $\mathbf{T}_{\mathrm{C}}\left({ }^{\circ} \mathbf{C}\right)$ & $\begin{array}{l}37.4 \pm \\
0.3\end{array}$ & $\begin{array}{l}37.4 \pm \\
0.4\end{array}$ & $\begin{array}{l}37.5 \pm \\
0.2\end{array}$ & $\begin{array}{l}37.2 \pm \\
0.3\end{array}$ & $\begin{array}{l}37.3 \pm \\
0.3\end{array}$ & $\begin{array}{l}37.2 \pm \\
0.2\end{array}$ & $\begin{array}{l}37.1 \pm \\
0.3\end{array}$ & $\begin{array}{l}37.3 \pm \\
0.3\end{array}$ & $\begin{array}{l}37.2 \pm \\
0.2\end{array}$ \\
\hline $\begin{array}{l}\text { H.R.M } \\
\text { (b.p.m) }\end{array}$ & $\begin{array}{l}137 \pm \\
17\end{array}$ & $\begin{array}{l}138 \pm \\
13\end{array}$ & $\begin{array}{l}138 \pm \\
10\end{array}$ & $\begin{array}{l}82 \pm \\
11\end{array}$ & $\begin{array}{l}90 \pm \\
29\end{array}$ & $\begin{array}{l}80 \pm \\
13\end{array}$ & $\begin{array}{l}161 \pm \\
9\end{array}$ & $\begin{array}{l}167 \pm \\
9\end{array}$ & $\begin{array}{l}169 \pm \\
7\end{array}$ \\
\hline
\end{tabular}


34.0
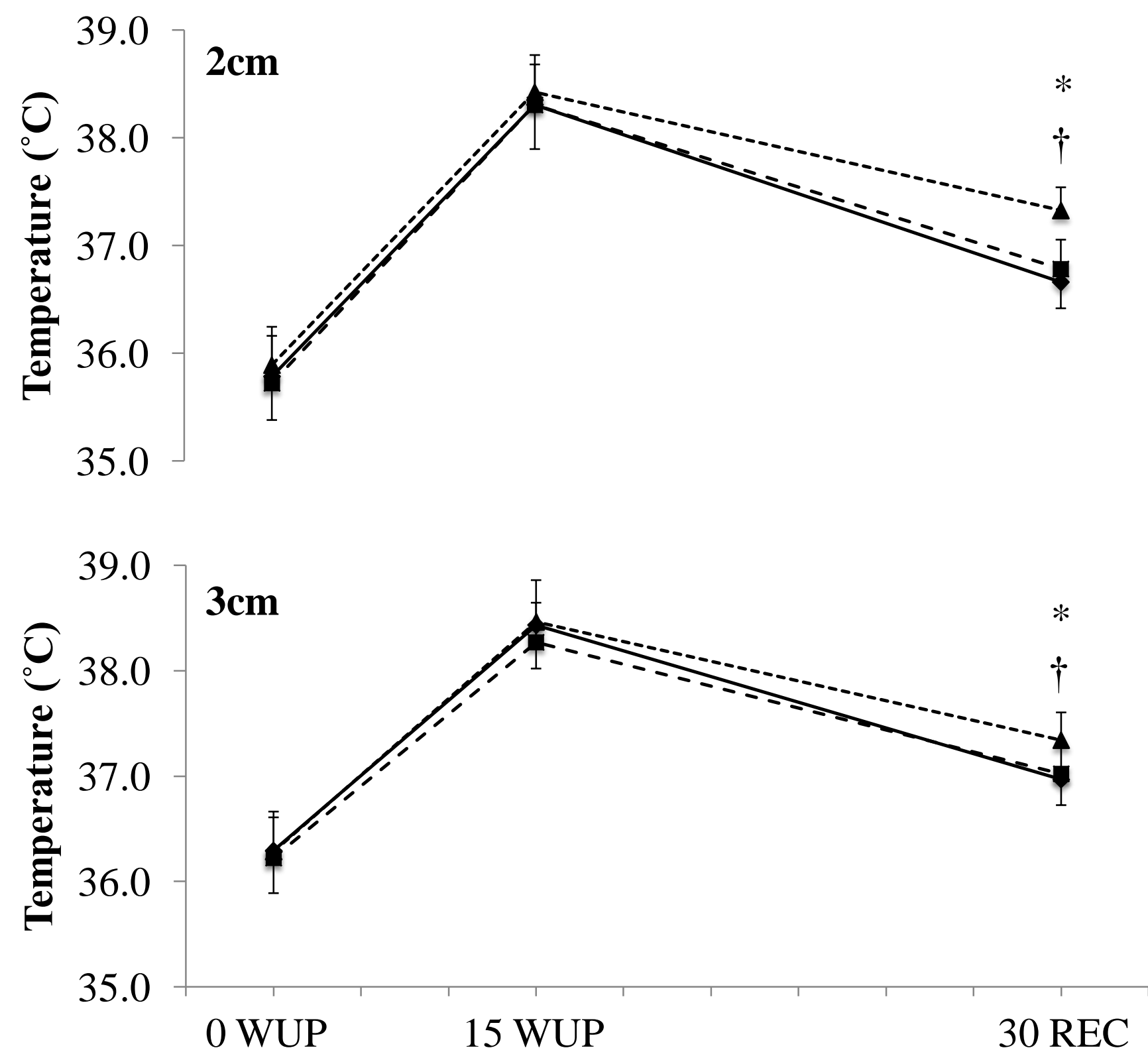


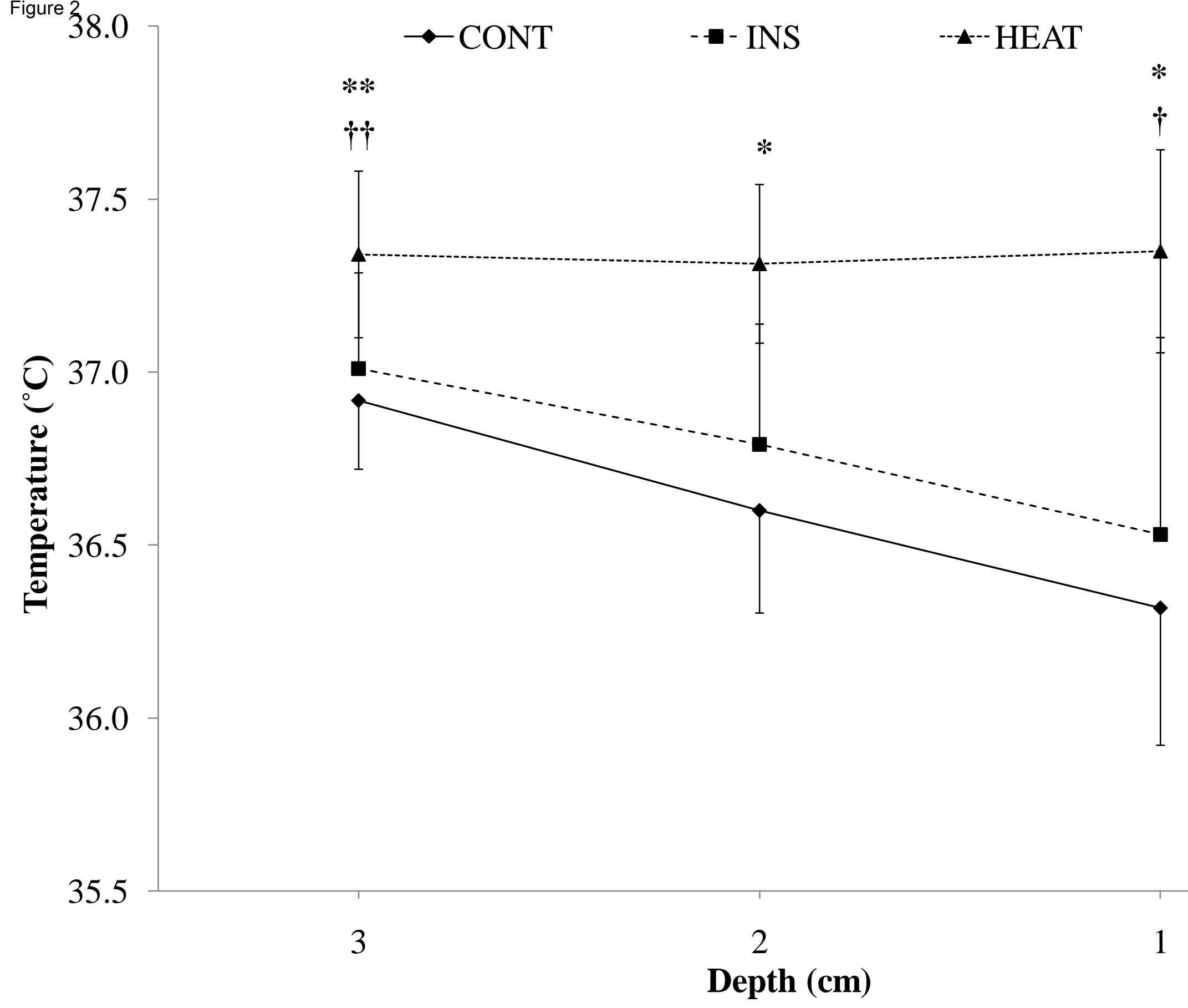




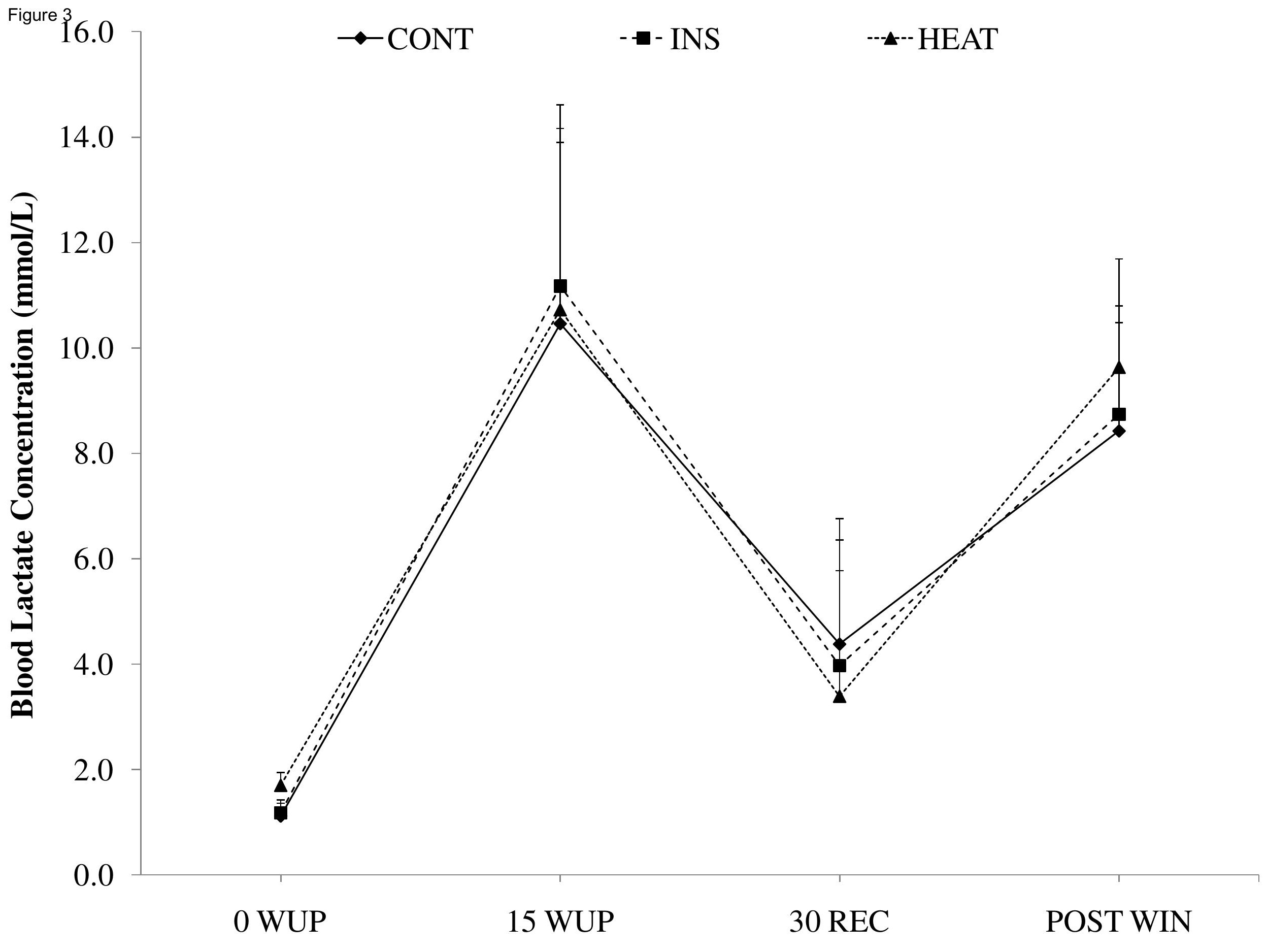


Figure 4

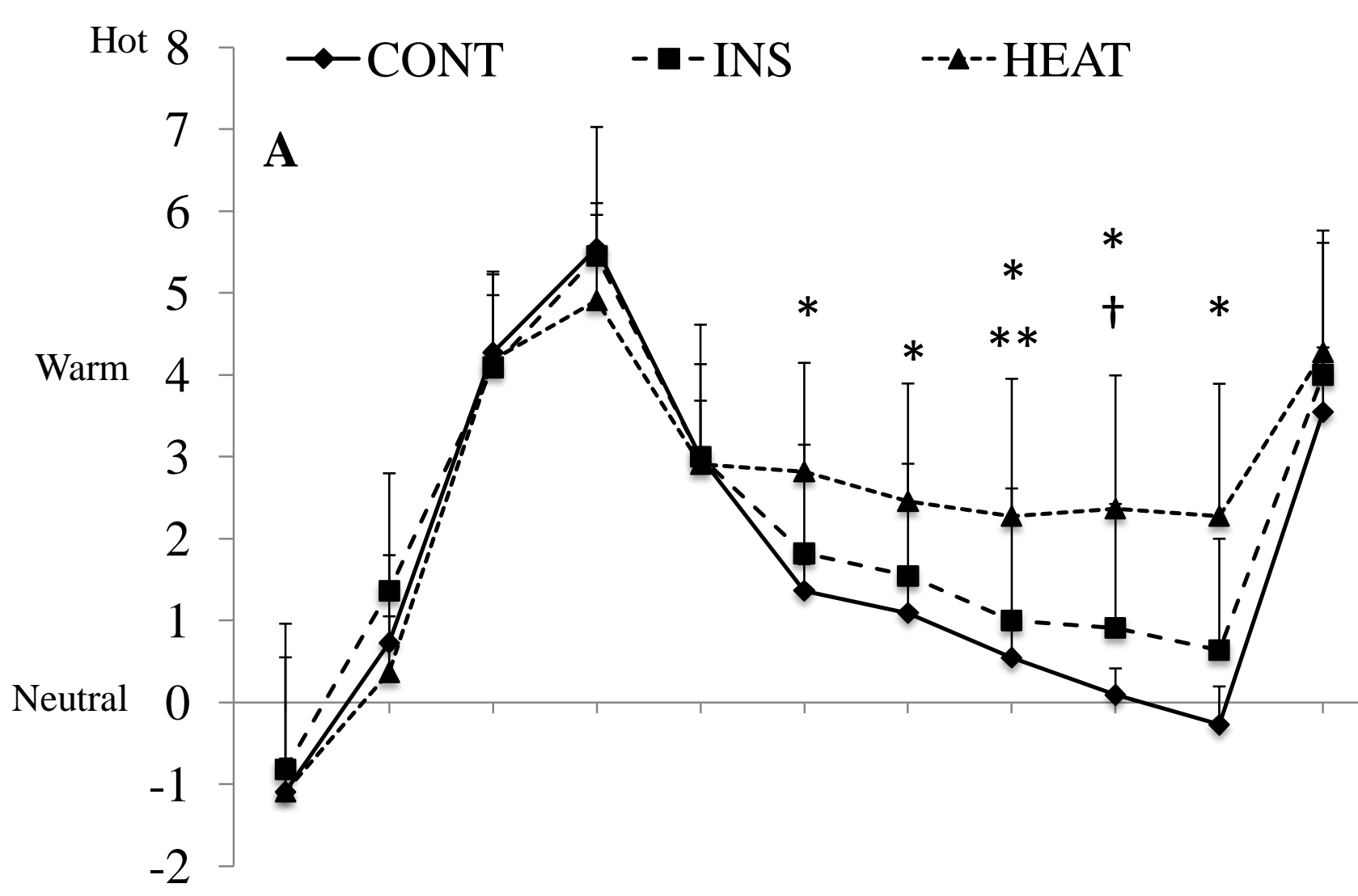

Uncomfortable 4

שֶ

B

Comfortable 0

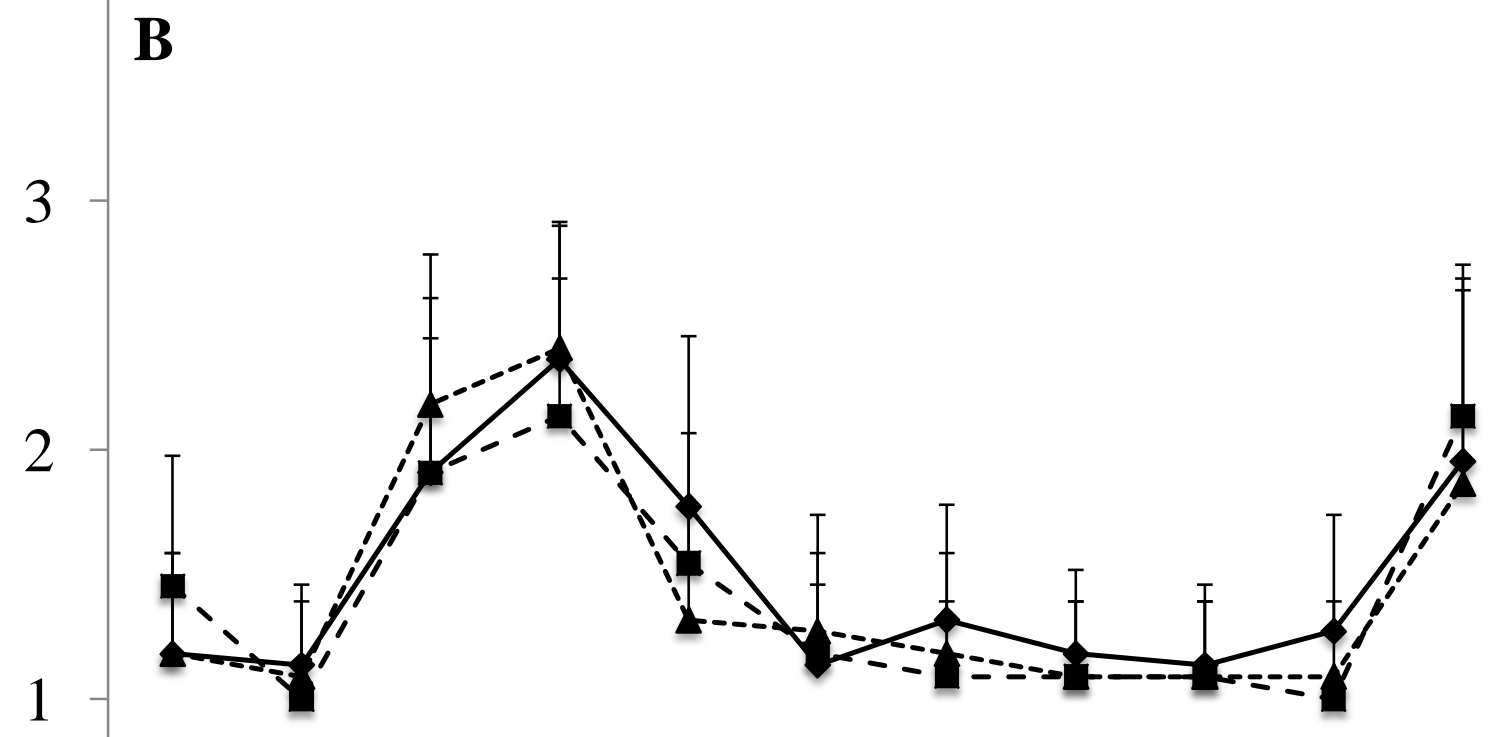

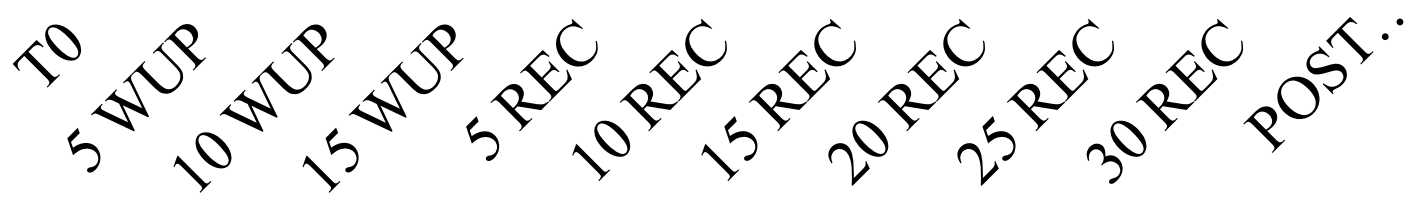

